BJS

\title{
The Pig as a Preclinical Model for Laparoscopic Vagus Nerve Stimulation.
}

\begin{tabular}{|r|l|}
\hline Journal: & British Journal of Surgery \\
\hline Manuscript ID: & Draft \\
\hline Wiley - Manuscript type: & Original Article \\
\hline Complete List of Authors: & $\begin{array}{l}\text { nolthuis, albert; University hospitals Leuven, Department of Abdominal } \\
\text { Surgery } \\
\text { Stakenborg, Nathalie; University hospitals Leuven, Translational Research } \\
\text { Center for GastroIntestinal Disorders (TARGID) } \\
\text { D'Hoore, Andre; University hospitals Leuven, Department of Abdominal } \\
\text { Surgery } \\
\text { Boeckxstaens, Guy; University hospitals Leuven, Translational Research } \\
\text { Center for GastroIntestinal Disorders (TARGID) }\end{array}$ \\
\hline Keywords: & $\begin{array}{l}\text { vagus nerve stimulation, abdominal vagus nerve, postoperative ileus, } \\
\text { porcine model, laparoscopy }\end{array}$ \\
\hline $\begin{array}{l}\text { Note: The following files were submitted by the author for peer review, but cannot be converted to } \\
\text { PDF. You must view these files (e.g. movies) online. }\end{array}$ \\
\hline VNS-pigs.wmv
\end{tabular}




\title{
Video is part of article
}

\section{The Pig as a Preclinical Model for Laparoscopic Vagus Nerve Stimulation.}

\author{
A.M. Wolthuis ${ }^{1}$, N. Stakenborg ${ }^{2}$, A. D’Hoore ${ }^{1}$, G.E. Boeckxstaens ${ }^{2}$ \\ ${ }^{1}$ Department of Abdominal Surgery, University Hospital Gasthuisberg Leuven \\ ${ }^{2}$ Translational Research Center for GastroIntestinal Disorders (TARGID), University Hospital \\ Gasthuisberg Leuven
}

Corresponding author:

\author{
A.M.Wolthuis \\ University Hospital Gasthuisberg Leuven \\ Herestraat 49 \\ 3000 Leuven \\ Belgium \\ Tel. +3216344265 \\ Fax. +3216344832 \\ E-Mail: albert.wolthuis@uzleuven.be
}

Category: Experimental paper 


\section{Abstract}

\section{Background}

Cervical vagus nerve stimulation (VNS) prevents manipulation-induced intestinal inflammation and improves intestinal transit in a mouse model of postoperative ileus (POI). Cervical stimulation, however, is accompanied by cardiovascular and respiratory side effects. In view of potential clinical application, we therefore evaluated the feasibility to stimulate the abdominal vagus nerve via laparoscopic approach in a porcine model.

\section{Methods}

Six pigs were used in a non-survival study to test the feasibility of laparoscopic posterior VNS. Two cardiac pacing electrodes were positioned around the abdominal vagus nerve and connected to a stimulator. All procedures were timed and videotaped and technical difficulties were noted. A validated National Aeronautics and Space Administration Task Load Index (NASA-TLX) questionnaire was used to evaluate the task and workload.

\section{Results}

The procedure was completed in all 6 pigs with 4-port laparoscopic technique. In all pigs, the vagus nerve was identified and isolated, followed by positioning of the electrodes. Median operating time was 16 minutes (range: 8-33 minutes) and median NASA-TLX was 31 (range: 11-74). No major complications were encountered. Technical difficulties included difficult exposure of the region of interest due to voluminous left liver lobes $(\mathrm{n}=1)$ and minor bleeding which hampered visualization $(\mathrm{n}=1)$.

\section{Conclusion}

In a porcine model, laparoscopic VNS of the abdominal vagus nerve is feasible with cardiac pacing electrodes and may lead to a similar novel approach in humans in the near future. 


\section{Background}

Postoperative ileus (POI) after abdominal surgery remains a leading cause of delayed recovery of gastrointestinal function leading to prolonged hospital stay ${ }^{1,2}$. POI is characterized by impaired gastrointestinal motility resulting from an inflammatory response located in the muscularis of the intestine. This inflammatory response is triggered by manipulation of the intestine during surgery. Previous studies in a mouse model clearly demonstrated that reduction of the inflammatory response was accompanied by recovery of gastrointestinal transit and shortening of $\mathrm{POI}^{3-6}$. Therefore, therapeutic strategies to prevent or shorten POI should aim to prevent the occurrence of surgery-induced intestinal inflammation. In 2000, a novel approach to modulate the immune system was introduced by the Tracey group $^{7}$. Vagal nerve stimulation (VNS) improved survival and reduced pro-inflammatory cytokine release in a mouse model of sepsis. This beneficial effect was mediated by the release of acetylcholine binding to nicotinic receptors on splenic macrophages. Hence the term 'cholinergic anti-inflammatory pathway' was introduced ${ }^{8}$. Previously, we extended this finding to the gastrointestinal tract and showed that VNS during 5 minutes immediately before surgery effectively reduced intestinal inflammation induced by surgery, leading to a faster recovery of gastrointestinal function in mice $\mathrm{e}^{3,5,6,9,10}$. VNS in humans undergoing abdominal surgery could therefore be an innovative strategy in an attempt to reduce POI and optimize postoperative outcome, as the vagus nerve innervates the gastrointestinal tract until the left colonic flexure. However, this procedure should be minimally invasive, cheap and feasible. Although electrical stimulation of the vagus nerve in the neck is currently used as treatment of epilepsy, depression, and migraine, this technique is designed for chronic stimulation with implantation of a coiled electrode around the nerve. Moreover, it is associated with side effects such as cough and hoarseness ${ }^{11}$. Alternatively, electrical stimulation could also be applied to the abdominal vagus nerve during surgery. The 
abdominal vagus nerve is indeed easily accessible as it runs along the esophagus entering the abdomen in the esophageal hiatus. This approach would avoid cervical vagus nerve dissection and it does not have the risk of triggering above-mentioned side effects. In order to pave the way for VNS as treatment of POI in humans, the aim of this study was to test the feasibility of laparoscopic VNS of the abdominal vagus nerve in pigs.

\section{Methods}

Animal model

Six Landrace pigs weighing approximately $40 \mathrm{~kg}$ were used. Each adult pig underwent deep surgical anesthesia with isoflurane $100 \%$ in supine position. The pigs were intubated and closely monitored with 3-lead ECG and pulse-oxymetry. The same surgical procedures were performed in each pig by the same surgeon (AW). This study was approved by the Animal Care and Animal Experiments Committee of KU Leuven (Leuven, Belgium).

\section{Laparoscopic VNS of the posterior vagus nerve branch in pigs}

A pneumoperitoneum was created with a Veress needle in the umbilicus by insufflating $\mathrm{CO}_{2}$ at a rate of 1-3 1/min to $15 \mathrm{mmHg}$. A 4-port laparoscopic approach was used (Fig. 1). The pig was placed in reversed-Trendelenburg position and the left liver lobes were retracted. After identification of the esophagogastric junction, the lesser omentum and the esophageal hiatus were opened, the right diaphragmatic crus was identified, and the posterior vagus nerve was dissected free from the esophagus. The tip of a surgical glove was put underneath the nerve to prevent leakage of current in the surrounding tissues. Two cardiac pacing wires (Streamline ${ }^{\mathrm{tm}}$, model 6494, Medtronic Inc., USA) were placed around the nerve at a distance of $1 \mathrm{~cm}$ from each other. The other end of the wires was extracted through the abdominal wall to be connected to an external stimulator (Keithley 6221-stimulator, Tektronix company, Cleveland, OH, USA). The procedure was timed and videotaped and technical difficulties 
were noted. The workload was assessed in 6 domains (mental demand, physical demand, temporal demand, performance, effort, and frustration levels) using a validated 10-point National Aeronautics and Space Administration (NASA) Task Load Index (TLX) questionnaire. The NASA-TLX is measured using a web-based scoring form (http://keithv.com/software/nasatlx/nasatlx.html). This is a multidimensional assessment tool that rates perceived workload, in order to assess a task and other aspects of performance. The surgical technique was described in detail with video documentation. All wounds were closed and the pigs were sacrificed with an intravenous injection of $\mathrm{T} 61^{\circledR}$ (MSD, Animal Health, Brussels, Belgium; embutramide $200 \mathrm{mg} / \mathrm{ml}$, mebenzoniumiodide $50 \mathrm{mg} / \mathrm{ml}$, tetracain hydrochloride $5 \mathrm{mg} / \mathrm{ml}$ ).

\section{Results}

The procedure was successfully completed in all 6 pigs. There were no conversions and no extra trocars were necessary. The posterior vagus nerve, running along the posterior side of the esophagus, could be identified and isolated in all pigs (Table 1). To better illustrate the procedure, a documented video with clear demonstration of the technique is enclosed (Video). Median operating time was 16 minutes (range: 8-33 minutes) and median NASA-TLX was 31 (range: 11-73.7). Operating time and NASA-TLX gradually decreased with increasing experience in each following pig (Fig. 2). Operating time decreased from 33 minutes in the first procedure to 8 minutes in the sixth procedure. In line with the operating time, the NASATLX decreased with increasing experience. Technical difficulties included difficult exposure due to voluminous left liver lobes $(n=1)$ and minor bleeding which hampered visualization $(n=1)$ in 2 different pigs.

\section{Discussion}


This animal feasibility study shows that using a simple 4-port laparoscopic technique, the abdominal vagus nerve can be identified, isolated and stimulated with cardiac pacing electrodes. Placement of a surgical glove fingertip and cardiac pacing wires required minimal manipulation of the nerve, thereby reducing the risk of surgical damage to the nerve. The learning curve is short, as illustrated by the swift decrease in operating times and NASA-TLIndices. These findings are important, because abdominal VNS is a new domain in the quest to reduce or to prevent $\mathrm{POI}^{9}$, and hence pave the way to introduce this technique in the clinical arena. VNS has recently been shown to have potent anti-inflammatory properties leading to improvement or prevention of POI in a mouse model $1^{3,5,6,9,10}$. Translation of these findings to clinical care may not be that futuristic, especially as cervical VNS is already used as a therapeutic option in patients with refractory epilepsy, migraine, and neuropsychiatric disorders $^{12-16}$. However, the incidence of infectious complications related to cervical VNS is around $5 \%{ }^{17}$. Moreover, in addition to neck pain, voice alterations, and hoarseness, cervical VNS can cause cardiovascular and respiratory side effects ${ }^{18-20}$. The latter and the need for an extra cervical incision make this approach less attractive in a POI setting. Moreover, VNS only needs to be applied for a few minutes, in contrast to chronic VNS in neurologic conditions requiring implantable devices. Therefore, feasibility of abdominal VNS via laparoscopic approach was undertaken in a pig model. This animal model was chosen because porcine anatomy and physiology compare well to that of humans. In the present study, we were able to show that laparoscopic vagus nerve identification, dissection and isolation is feasible and easy to perform. Of note, the learning curve is short, quickly declining from 33 minutes in the first procedure to 8 minutes in the sixth procedure. Based on these data, we anticipate that in humans too a minimal learning curve will be required. Moreover, as the technique is easy to perform, it will only add about 10-15 minutes extra operating time. If future studies can demonstrate a similar significant improvement in postoperative recovery as 
preclinical data suggest, this minimal increase in operating time is to be ignored. Finally, the pacing electrodes used are cheap and the technique described to stimulate the nerve is simple. The electrode is gently put through and around the nerve and is easily removed after application of electrical current. To avoid leakage of current into the surrounding tissue, again an easy and cheap solution was chosen, i.e. introduction of a piece of surgical glove underneath the nerve, as illustrated in the video. Although theoretically the pacing wires may become dislodged or isolation of the electrodes may be incomplete, these potential problems were not encountered in the present study, mainly because the electrodes were positioned steadily around the nerve. Based on our previous studies abundantly showing that electrical or pharmalogical stimulation of the cholinergic anti-inflammatory pathway significantly reduced $\mathrm{POI}^{5,6}$, we anticipate that also in humans, VNS could be an attractive and cheap technique to shorten POI. However, before this technique can be implemented in humans, further animal research is essential to determine the optimal electrodes and stimulation settings for VNS. We believe that studying the effects of VNS on the heart rate in pigs is a necessary initial step towards applying abdominal VNS in patients to prevent POI. The data presented in the current paper represent the first step in this endeavor and illustrate that VNS of the abdominal vagus nerve during surgery may indeed be feasible and should be further explored.

\section{Conclusion}

The results of this pilot study suggest that laparoscopic vagus nerve stimulation is feasible in a porcine model. However, before implementing this approach into daily practice, safety, efficacy, and feasibility should be tested in patients.

\section{Acknowledgements}

The authors declare no conflict of interest. 


\section{References}

1. Baig MK, Wexner SD. Postoperative ileus: a review. Dis Colon Rectum 2004; 47: 516-526.

2. Boeckxstaens GE, De Jonge WJ. Neuroimmune mechanisms in postoperative ileus (Gut (2009), 58, (1300-11)). Gut 2010; 59: 140.

3. de Jonge WJ, van der Zanden EP, The FO, Bijlsma MF, van Westerloo DJ, Bennink RJ et al. Stimulation of the vagus nerve attenuates macrophage activation by activating the Jak2-STAT3 signaling pathway. Nature immunol 2005; 6: 844-851.

4. Lubbers T, Luyer MD, de Haan JJ, Hadfoune M, Buurman WA, Greve JW. Lipid-rich enteral nutrition reduces postoperative ileus in rats via activation of cholecystokinin-receptors. Ann Surg 2009; 249: 481-487.

5. The F, Cailotto C, van der Vliet J, de Jonge WJ, Bennink RJ, Buijs RM et al. Central activation of the cholinergic anti-inflammatory pathway reduces surgical inflammation in experimental post-operative ileus. Brit J Pharmacol 2011; 163: 1007-1016.

6. The FO, Boeckxstaens GE, Snoek SA, Cash JL, Bennink R, Larosa GJ et al. Activation of the cholinergic anti-inflammatory pathway ameliorates postoperative ileus in mice. Gastroenterol 2007; 133: 1219-1228.

7. Borovikova LV, Ivanova S, Zhang M, Yang H, Botchkina GI, Watkins LR et al. Vagus nerve stimulation attenuates the systemic inflammatory response to endotoxin. Nature 2000; 405: 458-462.

8. Van Der Zanden EP, Boeckxstaens GE, de Jonge WJ. The vagus nerve as a modulator of intestinal inflammation. Neurogastroenterol Motility 2009; 21: 6-17.

9. Matteoli G, Boeckxstaens GE. The vagal innervation of the gut and immune homeostasis. Gut 2013; 62: 1214-1222. 
10. Matteoli G, Gomez-Pinilla PJ, Nemethova A, Di Giovangiulio M, Cailotto C, van Bree SH et al. A distinct vagal anti-inflammatory pathway modulates intestinal muscularis resident macrophages independent of the spleen. Gut 2014; 63: 938-948.

11. Beekwilder JP, Beems T. Overview of the clinical applications of vagus nerve stimulation. J Clin Neurophysiol 2010; 27: 130-138.

12. Englot DJ, Chang EF, Auguste KI. Vagus nerve stimulation for epilepsy: a metaanalysis of efficacy and predictors of response. J Neurosurg 2011; 115: 1248-1255.

13. Groves DA, Brown VJ. Vagal nerve stimulation: a review of its applications and potential mechanisms that mediate its clinical effects. Neuroscience Biobehavioral Rev 2005; 29: 493-500.

14. Howland RH. Vagus Nerve Stimulation. Curr Behavioral Neuroscience Rep 2014; 1: 64-73.

15. Howland RH. New developments with vagus nerve stimulation therapy. $J$ Psychosocial Nurs Mental Health Serv 2014; 52: 11-14.

16. Morris GL, 3rd, Gloss D, Buchhalter J, Mack KJ, Nickels K, Harden C. Evidencebased guideline update: vagus nerve stimulation for the treatment of epilepsy: report of the Guideline Development Subcommittee of the American Academy of Neurology. Neurology 2013; 81: 1453-1459.

17. Kahlow H, Olivecrona M. Complications of vagal nerve stimulation for drug-resistant epilepsy: a single center longitudinal study of 143 patients. Seizure 2013; 22: 827-833.

18. Buschman HP, Storm CJ, Duncker DJ, Verdouw PD, van der Aa HE, van der Kemp P. Heart rate control via vagus nerve stimulation. Neuromodul 2006; 9: 214-220.

19. Matheny RG, Shaar CJ. Vagus nerve stimulation as a method to temporarily slow or arrest the heart. Ann Thor Surg 1997; 63: S28-29. 
20. Thompson GW, Levett JM, Miller SM, Hill MR, Meffert WG, Kolata RJ et al. Bradycardia induced by intravascular versus direct stimulation of the vagus nerve. Ann Thor Surg 1998; 65: 637-642.

\section{Figure captions}

Figure 1. Laparoscopic port positions in a pig. Note the 2 pacing wires.

Figure 2. Evolution of operating time and NASA-TLX in 6 consecutive pigs. 
Table 1. Operative details of 6 consecutive non-survival pigs.

\begin{tabular}{|c|c|c|c|c|c|}
\hline $\begin{array}{l}\text { Animal } \\
\text { number }\end{array}$ & $\begin{array}{l}\text { No. of } \\
\text { ports }\end{array}$ & $\begin{array}{l}\text { Vagus nerve } \\
\text { identification }\end{array}$ & $\begin{array}{l}\text { Isolation and } \\
\text { lead placement }\end{array}$ & $\begin{array}{c}\text { Duration } \\
\text { (min) }\end{array}$ & $\begin{array}{l}\text { NASA-TL- } \\
\text { Index }\end{array}$ \\
\hline $\begin{array}{l}\text { Non- } \\
\text { survival \#1 }\end{array}$ & 4 & yes & yes & 33 & 73.7 \\
\hline $\begin{array}{l}\text { Non- } \\
\text { survival \#2 }\end{array}$ & 4 & yes & yes & 21 & 57 \\
\hline $\begin{array}{l}\text { Non- } \\
\text { survival \#3 }\end{array}$ & 4 & yes & yes & 17 & 42 \\
\hline $\begin{array}{l}\text { Non- } \\
\text { survival \#4 }\end{array}$ & 4 & yes & yes & 15 & 20.3 \\
\hline $\begin{array}{l}\text { Non- } \\
\text { survival \#5 }\end{array}$ & 4 & yes & yes & 10 & 14 \\
\hline $\begin{array}{l}\text { Non- } \\
\text { survival \#6 }\end{array}$ & 4 & yes & yes & 8 & 11 \\
\hline
\end{tabular}

http://mc.manuscriptcentral.com/bjs 


\section{Summary}

\section{What is already known}

Cervical vagus nerve stimulation (VNS) prevents manipulation-induced intestinal inflammation and improves intestinal transit in a mouse model of postoperative ileus (POI). VNS in humans undergoing abdominal surgery could therefore be an innovative strategy in an attempt to reduce POI and optimize postoperative outcome.

\section{What is new}

To avoid cervical vagus nerve dissection, the novelty presented in this study is laparoscopic VNS of the abdominal vagus nerve in a porcine model. In view of potential clinical application, feasibility was tested.

\section{Potential impact on future practice}

After optimization of electrodes and stimulation settings, translation of these findings to clinical care may lead to a similar novel approach in humans in the near future. 


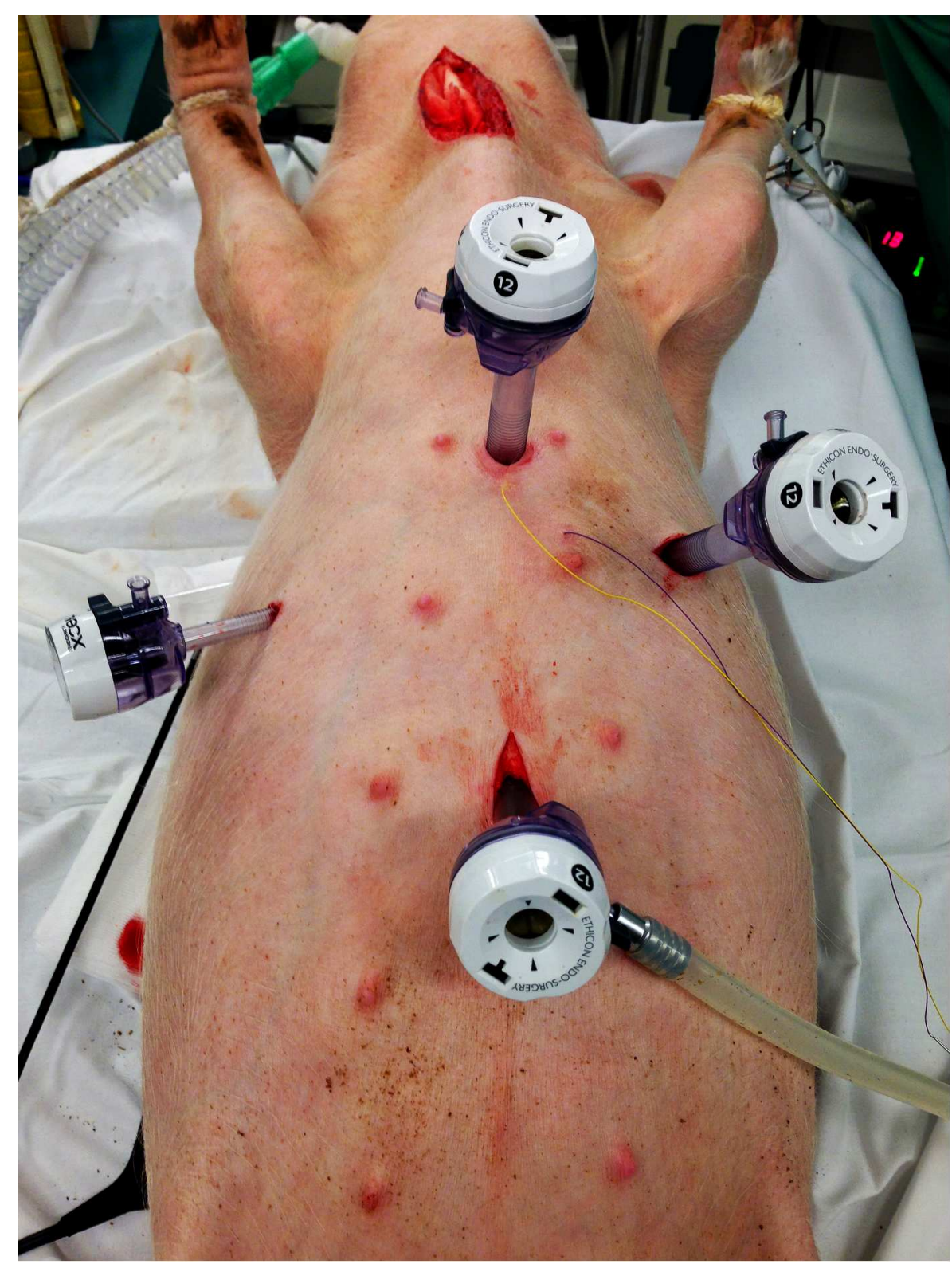

Laparoscopic port positions in a pig. Note the 2 pacing wires. $217 \times 290 \mathrm{~mm}(300 \times 300 \mathrm{DPI})$ 
Evolution of operating time and NASA-TLX in 6 consecutive pigs. $254 \times 190 \mathrm{~mm}(96 \times 96 \mathrm{DPI})$ 